\title{
Article \\ Modelling and Analysis of Power-Regenerating Potential for High-Speed Train Suspensions
}

\author{
Ruichen Wang ${ }^{1} \mathbb{D}$, Paul Allen ${ }^{1}$, Yang Song ${ }^{2, *} \mathbb{i}$ and Zhiwei Wang ${ }^{3}$ \\ 1 Institute of Railway Research, University of Huddersfield, Huddersfield HD1 3DH, UK; \\ r.wang@hud.ac.uk (R.W.); p.d.allen@hud.ac.uk (P.A.) \\ 2 Department of Structural Engineering, Norwegian University of Science and Technology, \\ 7491 Trondheim, Norway \\ 3 Technology and Equipment of Rail Transit Operation and Maintenance Key Laboratory of Sichuan Province, \\ Southwest Jiaotong University, Chengdu 610031, China; wangzw@swjtu.edu.cn \\ * Correspondence: yang.song@ntnu.no
}

Citation: Wang, R.; Allen, P.; Song, Y.; Wang, Z. Modelling and Analysis of Power-Regenerating Potential for High-Speed Train Suspensions. Sustainability 2022, 14, 2542. https:// doi.org/10.3390/su14052542

Academic Editor: Eklas Hossain

Received: 21 December 2021

Accepted: 18 February 2022

Published: 22 February 2022

Publisher's Note: MDPI stays neutral with regard to jurisdictional claims in published maps and institutional affiliations.

Copyright: (c) 2022 by the authors. Licensee MDPI, Basel, Switzerland. This article is an open access article distributed under the terms and conditions of the Creative Commons Attribution (CC BY) license (https:// creativecommons.org/licenses/by/ $4.0 /)$.

\begin{abstract}
Sustainable technologies in transport systems have attracted significant research efforts over the last two decades. One area of interest is self-powered devices, which reduce system integration complexity and cost with an undoubtedly great potential for improving adaptability and developing sustainability in railway transport systems. One potential solution is a regenerative suspension system, which enables the suspension movements and dissipated energy to be converted into useful electricity. This paper explores the application of hydraulic-electromagnetic regenerative dampers (HERDs) under realistic railway operating conditions for a high-speed train (HST). A vehicle-track-coupled dynamics model is employed to evaluate the regenerative power potential of an HST suspension over a range of operating conditions. The work considers typical route curvature and track irregularity of a high-speed line and speed profile. It was found that power could be regenerated at a level of up to 5-30 W and 5-45 W per generation unit when fitted to the primary and secondary dampers, respectively. Such power-regeneration levels were adequate to supply a variety of low-power-consumption onboard components such as warning lights and wireless sensors. Further analysis of the carbody loading level also was carried out. The analysis revealed that, in the case of a high-speed journey, poor track geometry, low curvature, and reduced carbody weight increased the quantity of regenerative energy harvested by the HERDs. It was concluded that a suitable HERD design could be achieved that could facilitate the development of a smart railway damper that includes both self-sensing and power-generation functions.
\end{abstract}

Keywords: power regeneration; high-speed train suspension; regenerative damper; sustainability

\section{Introduction}

Since the last century, researchers in academia have studied self-powered and energyharvesting solutions from three key sources: kinetic energy, thermal energy, and solar/light energy, to enable the possibility of converting ambient energy sources into electricity [1-5]. The innovative solutions began to attract global attention regarding the sustainability of the transport system [6]. The application of energy-harvesting solutions in road transportation favours the implementation of innovative and modern low-power-consumption onboard devices $[7,8]$. As an important transport mode, railways continued to increase in attractiveness as cost-effective means of passenger travel and transport of goods globally. To increase competitiveness with other transport modes, the railway system needs immediate attention and action towards a truly efficient and sustainable transport system within the market today.

To achieve the sustainable development and operational management of rail transport systems, onboard and trackside technology solutions have been developed in the fields of data collection, smart communication, health monitoring, and smart maintenance [9-13]. 
Their operation presents a challenging problem in that powering a monitoring device using a conventional approach would mean devices could not readily be installed in many circumstances due to harsh environmental conditions and inaccessible locations. A need has arisen for dependable onboard power sources generated in a sustainable way to power devices, therefore overcoming the restriction of traditional power supplies [14,15]. In contrast to road vehicles, the architecture of rail vehicles (trains and unpowered freight wagons) often necessitates the use of battery power for onboard monitoring/inspection devices, wired sensors, and other electronic devices, which are faced with battery power limitations [16]. This is unlike road vehicles, which can be powered by a battery that is charged by an engine-driven alternator. Relying on battery power, for example, when considering a health-monitoring system for railway dampers [17], whereby the rail vehicle is removed from operation when a time scheduled service is due. Consequently, under such a time-based or mileage-based approach, it is feasible that unnecessary battery replacement or recharging can be carried out, with a corresponding impact on operating costs and unnecessary maintenance. From this example, it becomes clear that the best way to achieve continuous real-time monitoring and onboard, condition-based maintenance (CBM) from the latest technologies/solutions is to design and develop self-powered/self-charging devices. Energy harvesting is a possible solution that can overcome the problem of supplying power in the implementation of onboard and wayside monitoring applications within a railway environment.

In recent years, a few studies on energy harvesting and alternative energy sources have focused on low-power and low-cost sensor applications, such as piezoelectric and motion-driven (linear and geared) electromagnetic solutions. De Pasquale et al. [18] proposed a self-powered sensing system with a piezoelectric generator that was intended to power the sensor nodes of a wireless sensor network (WSN). A peak power of $4 \mathrm{~mW}$ at a resonant frequency of $5.71 \mathrm{~Hz}$ was generated on a 1:4 scale railway bogie. Cho et al. [19] designed a similar piezoelectric harvester by utilising magnetic pendulum movement to charge the safety sensor of trains. In the optimal condition, a maximum average power density of $40.24 \mu \mathrm{W} / \mathrm{cm}^{3}$ was generated whilst recording the vibration and acceleration in the circuit design. Wang et al. [20] developed a piezoelectric harvester in the form of a series of piezoelectric layers between two consecutive sleepers. A maximum root mean square (RMS) power of $150 \mu \mathrm{W}$ was predicted at a train speed of $320 \mathrm{~km} / \mathrm{h}$. It was found that low cost, simple design, and easy installation were key characteristics for piezoelectric harvesters. However, piezoelectric harvesters are highly dependent on a railcar's speed and loading, which can present some drawbacks in terms of reliability due to low output power (microwatt or milliwatt level). In contrast to piezoelectric harvesters, motion-based electromagnetic harvesters have significant potential for generating more power. Nagode et al. [21] at Virginia Tech designed two types of electromagnetic harvesters (linear and geared concepts) for railroad applications. The results showed that the geared device generated up to $40 \mathrm{~W}$ RMS power, whereas the linear harvester could only reach approximately $0.76 \mathrm{~W}$ RMS power. Hou et al. [22] installed and tested a resonant harvester on a sectional slab track of the Guanzhou metro line, with a power density of $176.5 \mu \mathrm{W} / \mathrm{cm}^{3}$ and a current of $0.182 \mathrm{~A}$. The key drawbacks of linear electromagnetic methods are that the peak power only can be reached when the oscillation is close to the resonant frequency. Therefore, linear electromagnetic harvesters have been further developed using an alternative magnetic suspension with a spring-suspended oscillator to reduce the natural frequency and working frequency range [23-25]. Geared concepts of electromagnetic harvesters have been widely studied to harness the vibrational power from railway track deflections due to the passage of trains [26,27]. Pourghodrat et al. [28] presented several electromagnetic harvesters (geared, hydraulic, and cam-based) to supply the warning lights and healthmonitoring sensors for passing rail traffic. An average of $0.22 \mathrm{~W}$ was generated at a speed of $11.5 \mathrm{mph}$ for a loaded train. Such devices typically have limited power production and insufficient power at slow speeds and lower train-loading conditions. Li et al. [29] and Wang [27] designed and developed a mechanical motion rectifier (MMR)-based energy 
harvester for rail applications that generated up to $1.4 \mathrm{~W}$ average power with $10-25 \%$ mechanical efficiency in laboratory tests. In another similar study, Pan et al. [30] developed a ball-screw-based electromagnetic harvester with an MMR mechanism for responding to track deflections that obtained an average power of $2.24 \mathrm{~W}$ in field tests. The main drawbacks of the geared concept of the harvester were a complicated design (gear transmissions and misalignments), low energy-conversion efficiency, accelerated wear and fatigue (the degradation of components), and limited output power [31].

In addition to small energy-harvesting applications, regenerative suspensions have received increased research efforts in recent decades. Many researchers have designed linear and rotary electromagnetic motor-based regenerative suspension systems that can regenerate the vibrational energy and employ the oscillatory motion to drive the linear or rotary electromagnetic generator using mechanical and hydraulic transmissions [7,32,33]. Wang et al. [34,35] studied the energy dissipation of suspensions (primary and secondary), and indicated that a large amount of energy is dissipated in rail vehicle suspensions. With regards to the mechanical transmission-based regenerative suspension, Nagode et al. [21,36] designed and investigated three different types of mechanical-electromagnetic harvesters for rail vehicle applications, including a linear energy harvester that utilised magnets moving linearly inside of a suspension with coil springs and two ball-screw-based rotary harvesters that extracted vibrational energy out of linear motion through a planetary gearbox to convert the bidirectional linear motion into bidirectional or unidirectional rotation of a generator. Pan et al. [37] proposed a harvester design and onboard tests for rail vehicle applications using two sizes of gearheads in typical electromagnetic harvesters, which were installed in parallel with the primary suspension of a low-speed freight wagon. An average power of $1.3 \mathrm{~W}$ at a speed of $30 \mathrm{~km} / \mathrm{h}$ was produced in the test. With respect to the hydraulic-transmission-based regenerative suspension, Guo et al. [38] developed dynamic modelling and fabricated prototypes to study the characteristics of a hydraulic-based electromagnetic regenerative damper. Wang et al. $[39,40]$ proposed a similar hydraulic motion rectifier to convert dissipated vibrational energy into electricity, which clearly offered fast dynamic response and high energy conversion to overcome the drawback of large impact force and backlash. The proposed system achieved a power conversion efficiency of $40 \%$ for the hydraulic transmission-based regenerative shock absorber at an excitation frequency and amplitude of $1 \mathrm{~Hz}$ and $25 \mathrm{~mm}$, respectively. Regarding [7] and [41], it was found that the hydraulic transmission-based regenerative damper was suitable for all types of suspensions due to its benefits: (a) easy fabrication, (b) high potential power, (c) high sensitivity and controllability, (d) long service life, and (e) effective force absorbing, especially in the case of heavy railway vehicles.

Compared to mechanical-transmission-based regenerative dampers and other small-scale energy-harvesting technologies, the hydraulic-transmission-based regenerative damper is a promising solution, especially in railway vehicle suspensions, and has great potential to replace the conventional dampers completely and also harvest the vibrational energy during vehicle operation. However, one of the important challenges is increasing the power output of the regenerative damper under more realistic railway conditions to obtain sufficient power. The conversion efficiency is another challenge in regenerative dampers that requires more reliable designs and more efficient motion rectifiers and power-generation circuits. Regarding railway-suspension-based regenerative dampers, a vehicle-track coupled dynamics model with a regenerative damper is required to analyse the power potential and regeneration performance under various conditions. This paper is the first attempt to include the regenerative damper in the vehicle model and investigate the potential applicability with numerical simulations.

This paper is outlined as follows. After providing a review and update concerning energy-harvesting technologies, Section 2 describes the development of a vehicle-track coupled dynamics model and introduces the system design and systematic modelling of the proposed hydraulic-electromagnetic regenerative damper. Section 3 presents the 
simulation workflows and discusses the impact factors of different operating conditions. Conclusions are provided in Section 4.

\section{Modelling and Dynamics}

In this section, to advance suspension-based energy-harvesting technology in railway vehicles, a more comprehensive and accurate model of a regenerative hydraulicelectromagnetic shock-absorber system is proposed that precisely considers the effects of valve flow, fluid bulk modulus variation, accumulator smoothing, the influence of generator features, and losses and leakage of the motor. A hydraulic-electromagnetic regenerative damper (HERD) model is first analysed for the primary and secondary suspension systems of a detailed vehicle-track coupled dynamics model in the SIMPACK environment. The dynamic factors of the tracks, the traction, and gear transmission systems are also included within the vehicle-track coupled dynamics model (73 degrees of freedom (DOFs)) to increase the reliability and availability of the vehicle dynamics.

A vehicle-track coupled dynamics model considering the vehicle and regenerative damper interaction was developed to predict the power potential and power regeneration according to the multibody dynamics and the mechanical-hydraulic-electromagnetic coupling mechanism for a typical high-speed train. The cosimulations were carried out under various running conditions (curved track, track irregularity, speed profile, traction profile, and carbody loading conditions) to analytically characterise the proposed regenerative damper and compare the power capability of the vertical dampers of a high-speed train. As shown in Figure 1, SIMPACK scripting and MATLAB scripts were used to automate the analysis process. The automation generated a simulation run with the required vehicle-damper model and simulation parameters, and then began the cosimulation.

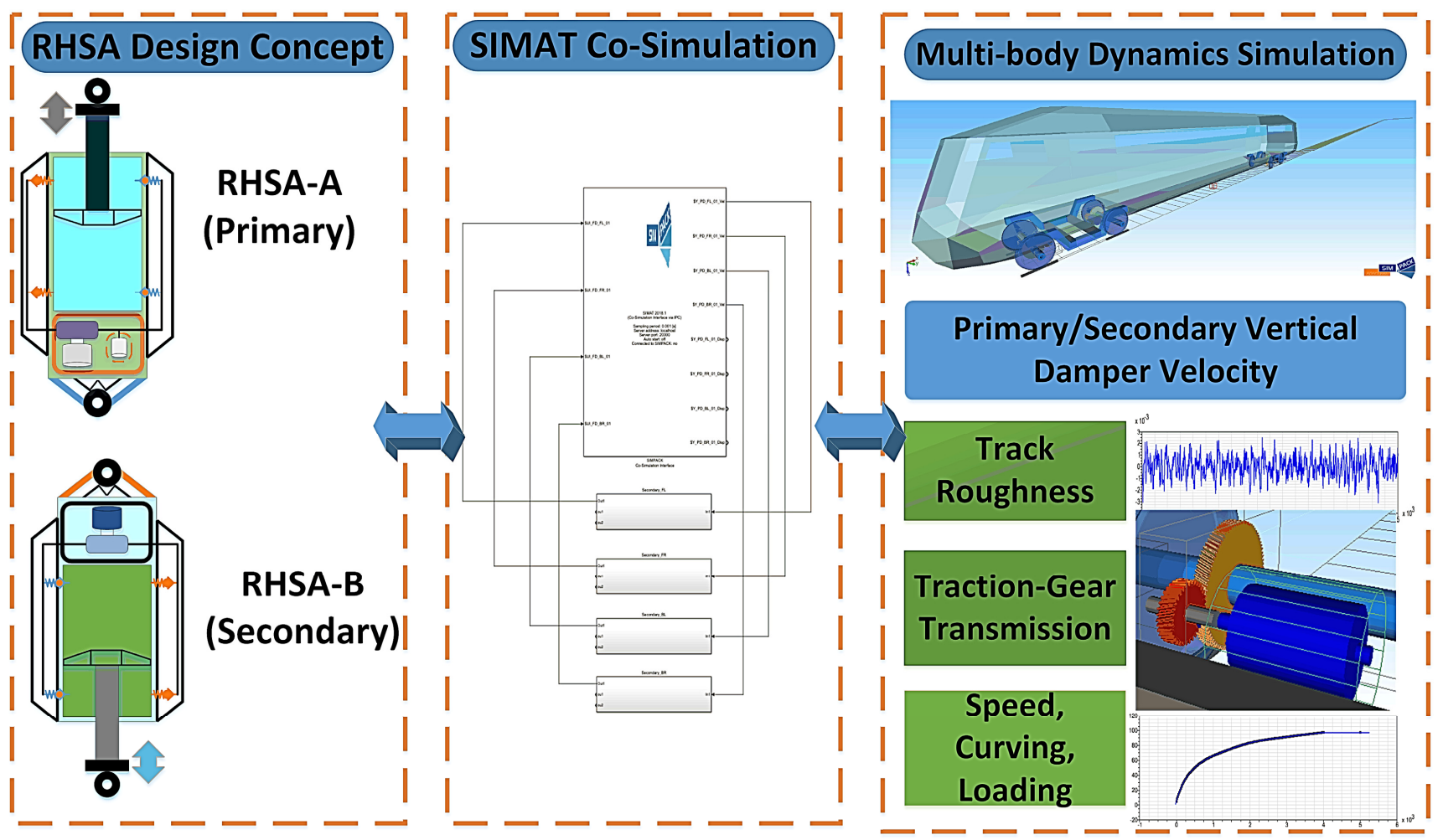

Figure 1. Schematic view of the cosimulation exchange process.

\subsection{Vehicle Suspension Dynamics}

To study the power regeneration of the primary and secondary vertical dampers, a detailed dynamic model was established according to the high-speed train's structural properties and working mechanisms. The vehicle model was composed of the carbody, bogie 
frames, wheelsets, and axle boxes. The model additionally contained traction transmission systems for driving the vehicle forward. The motor-car dynamics model was based on a previously published model [42-46]. In the present dynamics model, the kinematic constraints and suspension systems, such as the bump stop, spring stiffness, time-varying mesh stiffness, and the friction force of the gear pair, were implemented by nonlinear elements. The contact forces at the wheel-rail interface was simulated by the FASTSIM algorithm in the SIMPACK environment. Figure 2 illustrates the three-dimensional vehicle-track model based on the classical vehicle-track model.

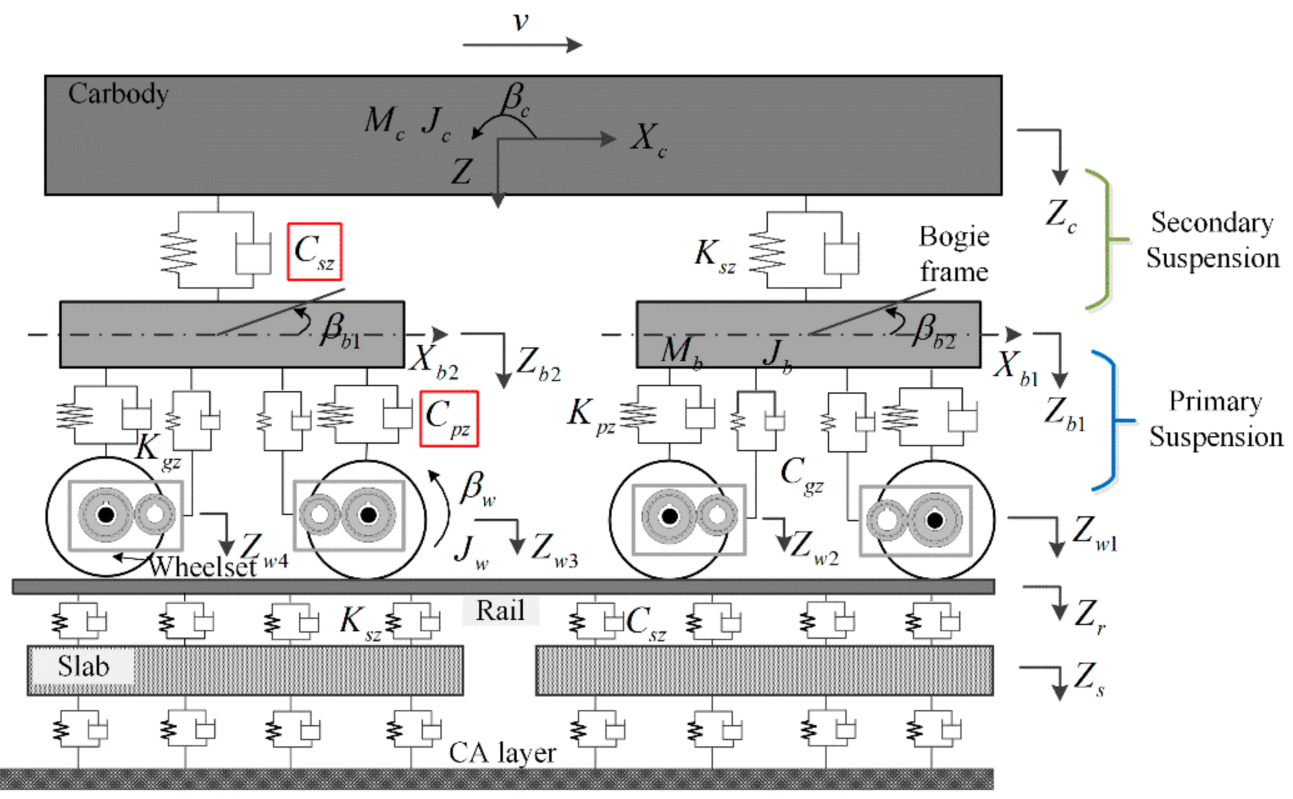

Figure 2. End view of three-dimensional vehicle-track coupled dynamics.

In the three-dimensional vehicle-track coupled dynamics model $[45,47]$, the springdamper elements handled the lumped masses' interaction forces. The primary vertical spring forces and damping forces between the axle box and bogie; namely, $F_{z f L}$ and $F_{z f R}$ on the left and right side, respectively, were calculated as follows:

$$
\left\{\begin{array}{c}
F_{z f L i}=K_{p z}\left(Z_{b n}-Z_{a L i}+(-1)^{i} l_{b} \beta_{b n}-d_{w} \phi_{b n}\right) \\
\quad+C_{p z}\left(\dot{Z}_{b n}-\dot{Z}_{a L i}+(-1)^{i} l_{b} \dot{\beta}_{b n}-d_{w} \dot{\phi}_{b n}\right) \\
F_{z f R i}=K_{p z}\left(Z_{b n}-Z_{a R i}+(-1)^{i} l_{b} \beta_{b n}+d_{w} \phi_{b n}\right) \\
+C_{p z}\left(\dot{Z}_{b n}-\dot{Z}_{a R i}+(-1)^{i} l_{b} \dot{\beta}_{b n}+d_{w} \dot{\phi}_{b n}\right)
\end{array}(i=1,2,3,4)\right.
$$

The secondary vertical spring forces and damping forces between the car body and bogie frame; namely, $F_{z b L}$ and $F_{z b R}$ on the left and right side, respectively, were calculated as follows:

$$
\left\{\begin{array}{c}
F_{z b L i}=K_{s z}\left(Z_{c}-Z_{b i}+d_{s} \phi_{b i}-d_{s} \phi_{c}+(-1)^{i} l_{c} \beta_{c}\right) \\
+C_{s z}\left(\dot{Z}_{c}-\dot{Z}_{b i}+d_{s} \dot{\phi}_{b i}-d_{s} \dot{\phi}_{c}+(-1)^{i} l_{c} \dot{\beta}_{c}\right) \\
F_{z b R i}=K_{s z}\left(Z_{c}-Z_{b i}+d_{s} \phi_{b i}-d_{s} \phi_{c}+(-1)^{i} l_{c} \beta_{c}\right) \\
+C_{s z}\left(\dot{Z}_{c}-\dot{Z}_{b i}-d_{s} \dot{\phi}_{b i}+d_{s} \dot{\phi}_{c}+(-1)^{i} l_{c} \dot{\beta}_{c}\right)
\end{array}(i=1,2)\right.
$$

In the above equation, when $i=1,2, n=1$; and when $i=3,4, n=2$. In addition, the subscripts of the motion variables $X, Y, Z, \varphi, \psi$, and $\beta$ are explained as follows: $c$-carbody; $b$-bogie frame; $m$-traction motor; $g$-gearbox; $w$-wheel; $a$-axle box; $L$-left; and $R$-right. One dot above the variables represents a first-order differential operation. Fur- 
thermore, the details of the motion variables are shown in Table 1. The present vehicle-track model was validated through a comparison with the measured accelerations of a carbody collected from field tests in the authors' previous works [44,48].

Table 1. Degrees of freedom of the high-speed-vehicle dynamic model.

\begin{tabular}{ccccccc}
\hline Vehicle Component & Longitudinal & Lateral & Vertical & Roll & Yaw & Pitch \\
\hline Carbody & $X_{c}$ & $Y_{c}$ & $Z_{c}$ & $\phi_{c}$ & $\psi_{c}$ & $\beta_{c}$ \\
\hline Bogie Frame $(i=1,2)$ & $X_{b i}$ & $Y_{b i}$ & $Z_{b i}$ & $\phi_{b i}$ & $\psi_{b i}$ & $\beta_{b i}$ \\
\hline Motor $(i=1-4)$ & $X_{m i}$ & $Y_{m i}$ & $Z_{m i}$ & - & - & $\beta_{m i}$ \\
\hline Gearbox $(i=1-4)$ & $X_{\mathrm{ghi}}$ & $Y_{\mathrm{ghi}}$ & $Z_{\mathrm{ghi}}$ & - & - & $\beta_{\mathrm{ghi}}$ \\
\hline Pinion $(i=1-4)$ & $X_{p i}$ & $Y_{p i}$ & $Z_{p i}$ & $\phi_{p i}$ & - & $\beta_{p i}$ \\
\hline Wheelset $(i=1-4)$ & $X_{w i}$ & $Y_{w i}$ & $Z_{w i}$ & $\phi_{w i}$ & $\psi_{w i}$ & $\beta_{w i}$ \\
\hline
\end{tabular}

Note: in addition to the DOFs in the table, the longitudinal motion of the axle box also was considered.

\subsection{Modelling of the HERDs}

Conventional vertical dampers result in most of the energy being wasted through resistance due to track roughness, friction of moving parts, and thermal losses, but the kinetic energy loss in the dampers is also one of the notable causes of energy loss in vehicles. Conventional hydraulic shock absorbers convert the vibrational energy into heat to ensure ride comfort and running safety, and this heat energy is then lost to the atmosphere.

According to previous experience, one of the benefits of regenerative dampers is that they can reduce the costs of the vehicle by saving petroleum fuel or electrical energy. The oscillation in vertical dampers can be converted into recoverable electricity that can power other devices or recharge the battery by means of a rotary or linear electromagnetic motor. The hydraulic-electromagnetic regenerative damper does have some disadvantages. One, the complex pipeline system has considerable weight and requires more installation room. Two, hose leaks and ruptures may disable the whole system (as with conventional viscous dampers as well). Three, the responding bandwidth of the hydraulic system is narrow, which confines the suspension performance. In this paper, the regenerative power capability and feasibility were investigated through numerical simulations. The power regeneration of primary and secondary vertical dampers was estimated at this initial stage in an attempt to provide an overview of a regenerative hydraulic suspension system.

As shown in Figure 1, the HERD model comprised a hydraulic cylinder, check valves, an accumulator, a hydraulic motor, pipelines, a generator, and an oil tank that could replace the traditional damper of the primary and secondary suspension system. The piston-rod diameter of the primary and secondary regenerative vertical damper body was designed in different sizes of $80-35 \mathrm{~mm}$ and $50-0 \mathrm{~mm}$ according to the study of the damper characteristics' relationship between damper force and damper velocity [35]. When the piston moved up and down, the fluid in the tank was forced to flow into the cylinder chambers. According to the hydraulic rectifier, the fluid flowed through the pipeline (an arrangement of check valves). The hydraulic accumulator steadied the oscillating flow to provide stable rotation of the hydraulic motor and generator, which was only used for the primary HERDs. Meanwhile, the generator outputted electrical power using the rotation of the hydraulic motor. The HERD hydrodynamic model was implemented in MATLAB Simulink, and interfaced with the SIMPACK models using the SIMAT cosimulation interface. This allowed SIMPACK to solve the dynamic responses, whilst MATLAB Simulink solved the performance of the regenerative damper (damping force and power regeneration). At each calculation timestep, y-outputs (measurements) were sent to MATLAB and $u$-inputs (actuator forces) were returned to SIMPACK, as represented in Figure 1. 


\subsubsection{Hydraulic Motor, Accumulator, and Generator}

The flow rate and pressure oscillated significantly within the model due to the different piston areas and annulus areas in the cylinder chambers, thereby causing asymmetrical fluid flows. In the hydraulic circuit, a hydraulic accumulator was applied to the motor's inlet, stabilising the flow's fluctuation. A check valve (one-way valve) rectified the outflow from the two chambers of the cylinder via the hydraulic accumulator to smoothen the high-pressure fluid before it passed through the motor to the drive generator.

As shown in Figure 3, the the gas chamber was preloaded at a pressure of $P_{p c}$. The behaviour of the accumulator can be expressed in terms of the variation of the flow, $Q_{a c}$; the pressure, $P_{a c f}$; and the volume, $V_{a c f}$ :

$$
\begin{gathered}
Q_{a c}=C_{a c} \sqrt{\left|P_{M}-P_{a c f}\right|} \Rightarrow \frac{d P_{a c f}}{d t}=\frac{k_{a c} P_{a c f} Q_{a c}}{V_{a c}-V_{a c f}} \\
P_{a c f} \leq P_{p c}, \quad V_{a c f}=0 ; P_{a c f}>P_{p c}, \quad V_{a c}\left(1-\frac{P_{p c}}{P_{a c f}}\right)^{1 / k_{a c}}
\end{gathered}
$$

where $C_{a c}$ is the accumulator constant, $V_{a c}$ is the capacity of the accumulator, and $k_{a c}$ is the gas specific heat ratio of the gas-charged accumulator.
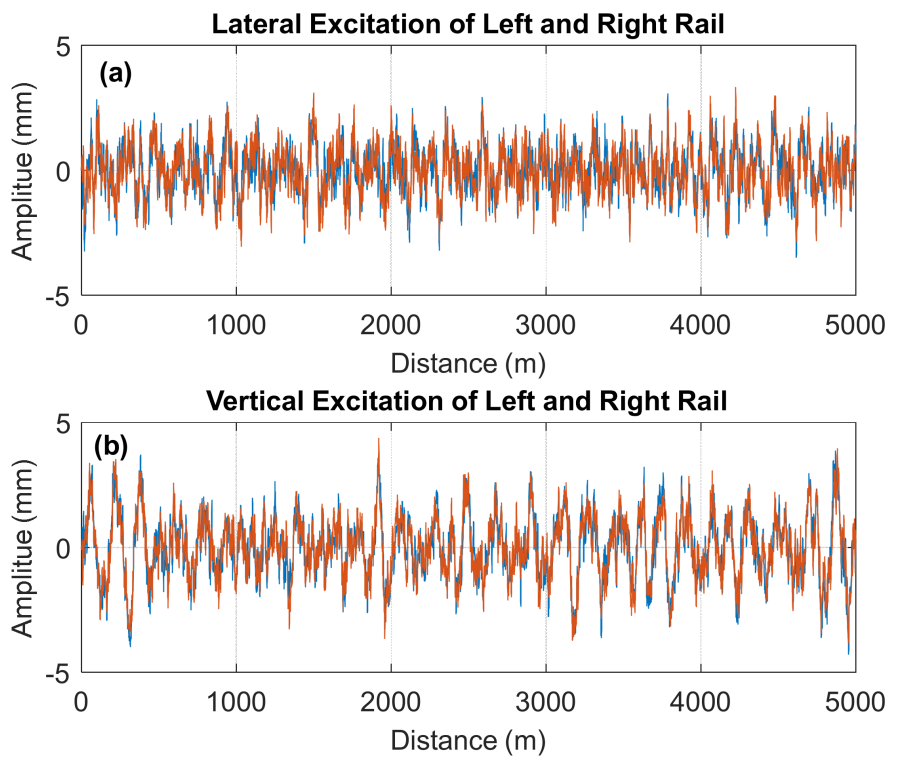

Figure 3. (a) Lateral and (b) vertical irregularities applied on both left and right rails.

Regarding the rotation of the motor shaft, the motor and generator shaft torque and the rotation velocity can be calculated as:

$$
\begin{gathered}
T_{M}=\frac{D_{M} P_{M} \eta_{M}}{2 \pi} \text { and } T_{G}=J_{t} \frac{d \omega}{d t}+K_{T} I \\
\omega_{M}=\frac{2 \pi Q_{M} \eta_{V}}{D_{M}} \text { and } \omega_{G}=\frac{E}{K_{E}}
\end{gathered}
$$

where $\eta_{M}$ is the mechanical efficiency of the hydraulic motor; $D_{M}$ is the hydraulic motor displacement; $J_{t}$ is the shaft moment of inertia, which was combined as one with the hydraulic motor, generator, and shaft coupling; KT is the torque coefficient; and KE is the constant electromotive voltage coefficient. The hydraulic motor was coupled with the electromagnetic generator, and the transmission ratio was assumed as 1:1 without 
considering the friction losses (the breakaway friction, Coulomb friction, viscous friction, etc.). According to Kirchhoff's voltage law, the electromotive force E can be calculated as:

$$
E=L_{G} \frac{d I}{d t}+I\left(R_{B}+R_{i n}\right)
$$

where $L_{G}$ is the internal inductance, $R_{B}$ is the external electrical load, and $R_{\text {in }}$ is the internal resistance of the generator. The motor pressure $P_{M}$ can be integrated as:

$$
P_{M}=\frac{4 \pi^{2} \eta_{V}}{D_{M}^{2} \eta_{M}}\left(\frac{K_{T} K_{E}}{R_{B}+R_{i n}} Q_{M}+J_{t} \dot{Q}_{M}\right) \approx \frac{4 \pi^{2} \eta_{V} K_{T} K_{E}}{D_{M}^{2} \eta_{M}\left(R_{B}+R_{i n}\right)} Q_{M}
$$

The following assumptions were made within the calculations:

(a) The size of the piston-rod cylinder (rebound and compression chambers) was assumed to be equivalent to the railway suspension tube, ignoring the heat exchange between the piston and inner cylinder surface under rapid cycling conditions.

(b) The external electrical load was assumed to be identical to the generator's internal load resistance to maximise the power-regeneration capability whilst providing the required consistency in damping force for the suspension system.

(c) Mechanical frictions, thermal losses, and leakage were not considered in the hydraulic circuits and hydraulic motor model flow. In a real application, when the fluid flows under variable pressure, the thermal losses caused by variation in the gas temperature will inevitably influence the gas behaviour.

(d) The pressures in the fluid chamber instead of those in the gas chamber were used to calculate the flow rate, which was reasonable due to the transient pressure balance inside the accumulator.

The typical parameters of the key components are shown in Table 2, together with their values. The numerical accuracy of the regenerated damper model was validated via experimental tests in [40]. Both the electrical and mechanical quantities showed good consistency with the experimental results. 
Table 2. Typical parameters of key components and their values.

\begin{tabular}{|c|c|c|c|c|}
\hline Key Component & Parameter & Symbol & Value & Units \\
\hline \multirow{5}{*}{ Hydraulic Cylinder } & Piston area (PD) & $A_{A}$ & 0.005 & $\mathrm{~m}^{3}$ \\
\hline & Piston ring area (PD) & $A_{B}$ & 0.0041 & $\mathrm{~m}^{3}$ \\
\hline & Piston area (SD) & $A_{A}$ & 0.002 & $\mathrm{~m}^{3}$ \\
\hline & Piston ring area (SD) & $A_{B}$ & 0.0016 & $\mathrm{~m}^{3}$ \\
\hline & Maximum cylinder stroke & & 0.15 & $\mathrm{~m}$ \\
\hline \multirow{4}{*}{ Hydraulic Motor } & Motor displacement (PD) & $D_{M}$ & 30 & $\mathrm{~m}^{3} / \mathrm{rev}$ \\
\hline & Motor displacement (SD) & $D_{M}$ & 18 & $\mathrm{~m}^{3} / \mathrm{rev}$ \\
\hline & Mechanical efficiency & $\eta_{M}$ & 95 & $\%$ \\
\hline & Volumetric efficiency & $\eta_{V}$ & 95 & $\%$ \\
\hline \multirow{8}{*}{ Generator } & Torque coefficient & $K_{T}$ & 0.93 & $\mathrm{Nm} / \mathrm{A}$ \\
\hline & Electromotive voltage coefficient & $K_{E}$ & 0.93 & $\mathrm{Vs} / \mathrm{rad}$ \\
\hline & Shaft moment of inertia & $J_{t}$ & 0.0002 & $\mathrm{Kg} \mathrm{m}^{2}$ \\
\hline & Internal inductance & $L_{G}$ & 0.03 & $\mathrm{H}$ \\
\hline & Internal resistance $(\mathrm{PD})$ & $R_{\text {in }}$ & 20 & $\Omega$ \\
\hline & External electrical load (PD) & $R_{B}$ & 20 & $\Omega$ \\
\hline & Internal resistance (SD) & $R_{\text {in }}$ & 10 & $\Omega$ \\
\hline & External electrical load (SD) & $R_{B}$ & 10 & $\Omega$ \\
\hline \multirow{5}{*}{ Hydraulic Rectifier } & Check-valve constant & $D_{C}$ & $2.533 \times 10^{-6}$ & - \\
\hline & Accumulator port constant (PD) & $C_{a c}$ & 0.0038 & - \\
\hline & Accumulator capacity (PD) & $V_{a c}$ & $5 \times 10^{-4}$ & $\mathrm{~m}^{3}$ \\
\hline & Gas specific heat ratio of the gas-charged accumulator (PD) & $k_{a c}$ & 1.4 & - \\
\hline & Accumulator preload pressure (PD) & $P_{p c}$ & 20 & bar \\
\hline
\end{tabular}

Note: PD stands for the parameters used in primary HERDs; SD stands for the parameters set in secondary HERDs.

\subsubsection{Power Conversion and Damping Force}

The effective input power of this system was taken as the sum of the piston damping force multiplied by the effective piston velocity $\dot{X}$ (SIMPACK vehicle model: suspension effective velocity).

$$
P_{\text {in }}=\left(P_{A} A_{A}+P_{B} A_{B}\right)|\dot{X}|
$$

where $P_{A}$ and $P_{B}$ represent the pressures in the rebound chamber and compression chamber, respectively.

The power regeneration is then expressed as:

$$
P_{\text {out }}=I^{2} R_{B}=\frac{4 \pi^{2} K_{E}^{2} \eta_{V}^{2} A_{i}^{2}|\dot{X}|^{2} R_{B}}{D_{M}{ }^{2}\left(R_{B}+R_{\text {in }}\right)^{2}} ; i=A, B
$$

Therefore, the power regeneration efficiency, $\eta$, can be expressed as:

$$
\eta=\frac{P_{\text {out }}}{P_{\text {in }}}=\frac{4 \pi^{2} K_{E}^{2} \eta_{V}^{2} A_{i}^{2}|\dot{X}| R_{B}}{D_{M^{2}}\left(R_{\text {in }}+R_{B}\right)^{2}\left(P_{A} A_{A}+P_{B} A_{B}\right)} ; i=A, B
$$


In addition, the damping force, $F_{D}$, of this system can be derived as:

$$
F_{D}=\left\{\begin{array}{l}
F_{D A}=\frac{4 \pi^{2} \eta_{V} K_{T} K_{E} A_{A}|\dot{X}|}{D_{M^{2} \eta_{M}\left(R_{i n}+R_{B}\right)}} ; P_{A} \geq P_{M} \\
F_{D B}=\frac{4 \pi^{2} \eta_{V} K_{T} K_{E} A_{B}|\dot{X}|}{D_{M^{2} \eta_{M}\left(R_{i n}+R_{B}\right)}} ; P_{B} \geq P_{M}
\end{array} \Rightarrow F_{D}=\frac{4 \pi^{2} \eta_{V} K_{T} K_{E} A_{i} \dot{X}}{D_{M}^{2} \eta_{M}\left(R_{i n}+R_{B}\right)} ; i=A, B\right.
$$

\subsection{Track Design and Irregularity}

The track parameters of a main high-speed line in China are listed in Table 3. The track was divided into six curve types with different radii, all of which made up different proportions of a $5 \mathrm{~km}$ unit length (expressed as percentages). The tangent line in Table 1 maintained the given track length, and its length percentage was obtained as 100 minus the sum of the other six length percentages. The whole track consisted of the tangent track and the curved tracks with different superelevations and transitions. Therefore, apart from the rail irregularities, the wheel-rail interaction differed on each part of the track. The percentages of the right and left curves were assumed to be identical along the whole line. Therefore, six track variants were used as one of the influencing factors in the simulation of the vehicle-damper model [44].

Table 3. Track characteristics of a high-speed railway line.

\begin{tabular}{ccc}
\hline Curve Radius (m) & Cant Deficiency $(\mathbf{m m})$ & Transition Length (m) \\
\hline$($ C1) 3000 & 150 & 380 \\
\hline$($ C2) 7000 & 150 & 540 \\
\hline$($ C3) 8000 & 135 & 500 \\
\hline (C4) 9000 & 125 & 490 \\
\hline (C5) 10,000 & 115 & 430 \\
\hline (C6) 12,000 & 100 & 370 \\
\hline
\end{tabular}

Concerning the irregularities, two types of rail irregularities were adopted in the numerical simulation. The first was realistic irregularities obtained from the WG high-speed line. The second was from six levels of the empirical spectrum of rail irregularities [49].

Track irregularities are a key source of track-induced vibration for a railway vehicle. Predefined track using a sinusoidal irregularity with a given frequency is insufficient for investigating the performance of a given suspension system or damper system; therefore, in this study, a more realistic track model was employed that was close to the level of the measured track irregularities.

The approach to representing track irregularities adopted in this work was based on power spectral density (PSD), a method developed by the Federal Railroad Administration (FRA) of the U.S. Dept. of Transportation that is based on a large amount of measurement data. Relating to the track irregularity, the PSDs were analysed according to even rational functions containing cut-off frequencies and irregularity constants, with wavelengths ranging from 1.524 to $304.8 \mathrm{~m}$. Six track classes were considered [49]. In general, apart from the rail irregularities, the wheel-rail interaction differed on each track due to different combinations of the curve radius, cant deficiency, and transition length. It was noted that the track design between the high and low rails (left and right curve) was assumed as identical throughout the simulation process. A track irregularity of a typical high-speed line (the measured vertical and lateral irregularity of the WG line is shown in Figure 3) was employed in the evaluation of the variable running speeds, tracks, and loading cases.

As shown in Table 4, the loading condition relates to the capacity of a railway vehicle and plays an important role in the railway system. For a high-speed train, the range of vehicle capacity highly depends on the journey distance. For short-distance, busy commuter routes, passengers may be seated and standing with luggage and other personnel 
belongings. For longer-distance journeys, there may be fewer standing passengers [50]. According to the change of loading condition, the mass and moment of inertia of the carbody were considered and recalculated for each vehicle model variant.

Table 4. The settings of the operating conditions and track characteristics.

\begin{tabular}{ll}
\hline & \multicolumn{1}{c}{ Operational Parameters and Track Characteristics } \\
\hline Track Design & See Table 3; six curves (C1 to C6) \\
\hline Track Irregularities & Six track classes [49] and measured WG line \\
\hline Speeds & $150,200,300,350$, and $380 \mathrm{~km} / \mathrm{h}$ and speed profiles $(0-380 \mathrm{~km} / \mathrm{h})$ \\
\hline Wheel Profile & S1002CN \\
\hline Rail Profile & $\mathrm{CN} 60$ \\
\hline Coefficient of Friction & 0.4 on tread and flange \\
\hline Loading Conditions & Tare (33.786 tons), fully seated (39.626 tons), fully laden, (41.226 tons) and crush laden (44.994 tons) \\
\hline
\end{tabular}

To explore the behaviour of the vehicle dynamics and quantity of power regeneration under a range of operating conditions, the following cases were considered.

The range of vehicle loading variations was classified into tare, fully seated, fully laden, and crush laden. The tare vehicle was equipped with all essential equipment and all staff on board. Fully seated meant all seats were occupied by passengers (73 passengers at $80 \mathrm{~kg}$ each) plus the tare condition for longer journeys. A fully seated load with another 20 standing passengers per vehicle created the fully laden load for short-distance peak-time travel. The crush laden load equated to a fully seated load plus more standing passengers, equivalent to four passengers per $\mathrm{m}^{2}$ in the designed standing area of $15.45 \mathrm{~m}^{2}$ [51].

\section{Simulation and Analysis}

The vehicle-damper dynamic modelling simulation approach was set up using a time/distance/speed vector within the SIMPACK and MATLAB interface. The vehicletrack parameters used in this study can be found in [44,48]. The track irregularity was used as the main excitation during the simulations for a group of track classes, including Class 1 to Class 6 (smooth to unsmooth). Track designs and vehicle-loading conditions were also implemented in each of the six combined cases as impact factors. The vehicle was run at speeds ranging from 150 to $350 \mathrm{~km} / \mathrm{h}$ with $50 \mathrm{~km} / \mathrm{h}$ intervals and a maximum designed speed of $380 \mathrm{~km} / \mathrm{h}$. The designed speed profile and traction profile were used for traction estimation and analysis, traction-gear transmission characteristics, and dynamic vehicle analysis. This study presents an overview of the regenerative power of the primary and secondary vertical dampers using the key influencing factors of operating speed, track irregularity, and vehicle-loading conditions.

The results within this section present the influence of the HERDs on the levels of predicted power potential, power regeneration, and efficiency for varying curve radii, track irregularities, running speeds (constant speeds and speed profile), and loading cases.

\subsection{Power-Regeneration Potential}

In order to comprehensively investigate the regenerated power (recoverable power) of the primary and secondary dampers, firstly, the power potential (equivalent to damper dissipated power) was quantified. As shown in Figure 4, the power potential was assumed to be identical to the power-regenerating potential, which was estimated by using a sensitivity analysis. This study was carried out based on regenerative primary and secondary dampers fitted to a high-speed train. Figure $4 \mathrm{a}, \mathrm{b}$ show the average potential power of the HERDs that could be recovered on the track for the case of $150-380 \mathrm{~km} / \mathrm{h}$ running speeds and Class 1-6 track irregularities. 

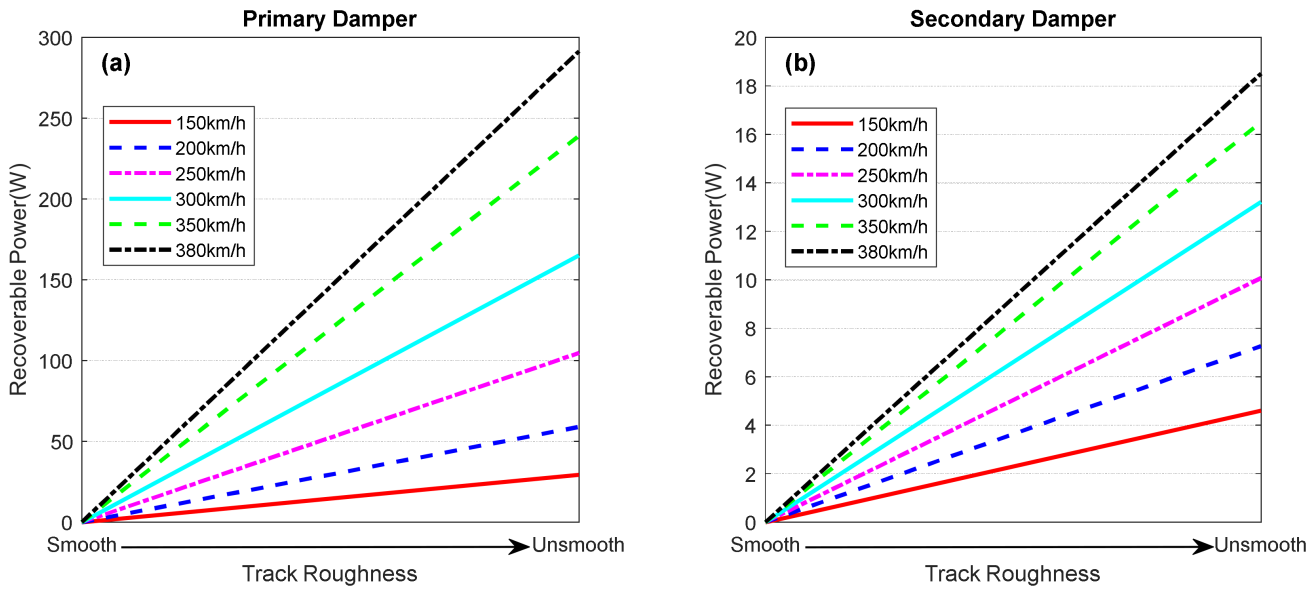

Figure 4. Average recoverable power of the HST primary and secondary dampers with variable track irregularities and running speeds. (a) Note Primary Damper; (b) Secondary Damper.

As expected, it was clear that the highest potential power was found at the fastest running speed combined with the most aggressive track irregularities. The estimation of the average potential power was approximately $291.4 \mathrm{~W}$ and $18.5 \mathrm{~W}$ for the primary and secondary damper, respectively. Logically, the results showed that the primary damper had the greatest potential for recoverable power compared to the secondary damper under the same conditions. This was because the RMS velocity of the primary damper was larger than that of the secondary, which meant the primary damper could potentially recover more kinetic energy (peak value: $542.4 \mathrm{~W}$ ), with values of the RMS damper velocity of 0.0466 and $0.0248 \mathrm{~m} / \mathrm{s}$ for the primary and secondary damper respectively (Figure $5 \mathrm{c}, \mathrm{d}$ ). It is well known that the damper in a secondary suspension will have very little movement. The secondary suspension aims mainly to improve ride comfort and ensure the vehicle remains within the allowed structure gauge. The primary suspension will be subjected to greater movements to isolate the bogie from the inevitable irregularities in the track and avoid excessive track forces. 

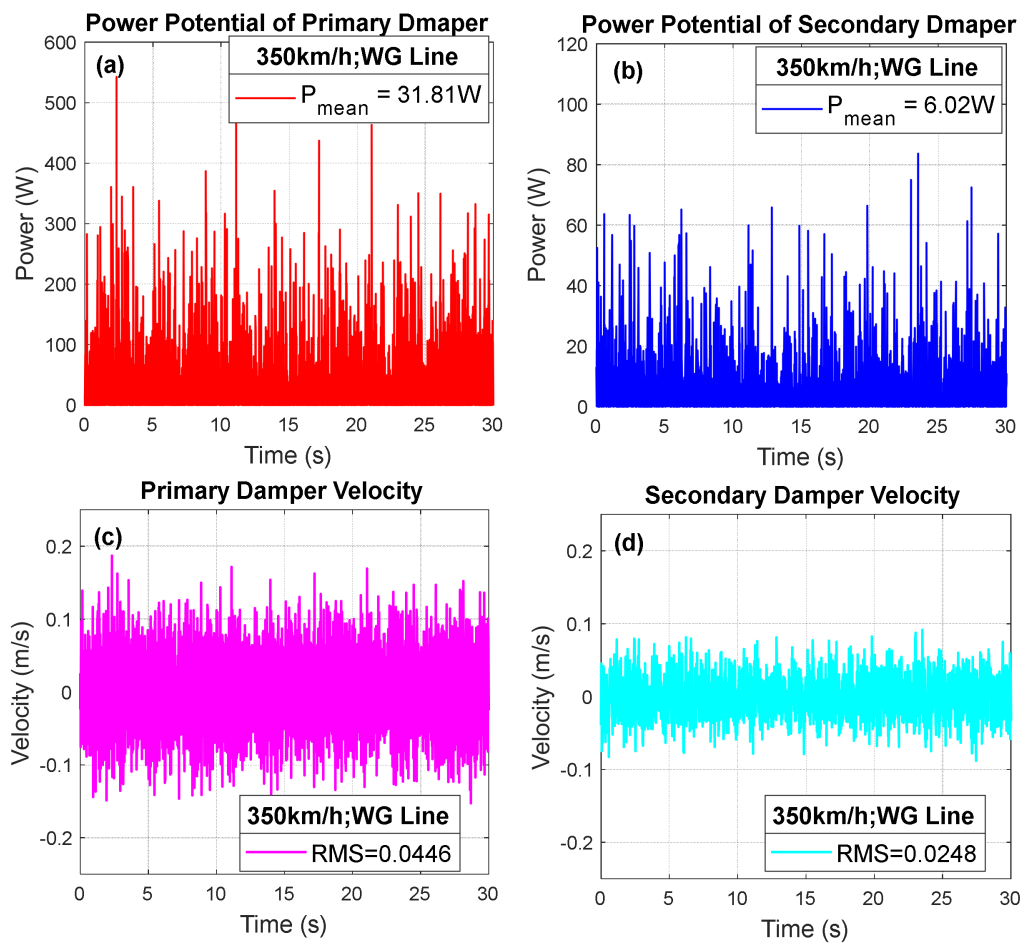

Figure 5. (a) Power potential of primary damper; (b) power potential of secondary damper; (c) primary damper velocity of the WG line at $350 \mathrm{~km} / \mathrm{h}$; (d) secondary damper velocity of the WG line at $350 \mathrm{~km} / \mathrm{h}$.

Further analysis of the power potential per primary and secondary damper was provided in the form of the instantaneous power at a constant speed of $350 \mathrm{~km} / \mathrm{h}$ with a typically measured track irregularity for a high-speed line. An average power of $31.81 \mathrm{~W}$ and $6.02 \mathrm{~W}$ could be produced, respectively, within a running time of $30 \mathrm{~s}$.

\subsection{Track Irregularity, Running Speed, and Curving Analysis}

The following analysis will explore the regenerated power and power efficiency characteristics with respect to the track irregularities, running speeds, and a range of curve radii and cant deficiencies. The following figures and table present the time-domain and distance-domain regenerative power outputs for the primary and secondary suspensions.

Figures 6 and 7 show the average and moving average RMS regenerated power of primary and secondary suspension systems for different track design cases, track irregularities, and running speeds. The average and moving average RMS power were mildly increased with the level of vehicle speed and unsmooth track, and faster running speed. The worst track irregularity could generate more excitation events and thus provide more potential power and regenerated power, but it seemed that the influencing factors considered had little effect on the average power-regeneration efficiency for both the primary and secondary HERDs, as shown in Table 5.

Table 5. Regenerative efficiency of HERDs for primary and secondary dampers.

\begin{tabular}{cccc}
\hline \multicolumn{4}{c}{ Regenerative Efficiency of HERDs in Different Conditions } \\
\hline Primary Damper & Speed & Track Irregularity & Curve \\
\hline Recoverable Efficiency & $45.06 \sim 45.89 \%$ & $44.61 \sim 45.86 \%$ & $\approx 45.38 \%$ \\
\hline Secondary Damper & Speed & Track Irregularity & Curve \\
\hline Recoverable Efficiency & $48.59 \sim 48.69 \% \%$ & $48.90 \sim 49.35 \% \%$ & $48.68 \sim 48.77 \%$ \\
\hline
\end{tabular}


In the case of curved track, as shown in Figure 6e, an increase in curve radius had no significant effect on the power regeneration of the primary damper, but the secondary damper's regenerated power slightly increased along with the value of the curve radius shown in Figure 6f; curve radii C1 to C6 are shown in Table 3. Regarding track irregularities, at a running speed of $350 \mathrm{~km} / \mathrm{h}$ on a straight track, a higher regenerated power of $28.99 \mathrm{~W}$ and $46.27 \mathrm{~W}$ could be regenerated in the primary and secondary suspensions, respectively, when the train ran on aggressive track irregularity 'I1'. A good average power level of up to $30.03 \mathrm{~W}$ was achieved in the primary damper when the vehicle travelled at $380 \mathrm{~km} / \mathrm{h}$ on a measured high-speed track ('WG Line'). This clearly showed that in this case, the regenerated power in the secondary suspension system had great potential to recharge electronic equipment or batteries.

According to the function of the primary vertical damper, it aimed to isolate the trackrelated excitation from wheelsets transmitted to the bogie frame, and thus a considerable amount of power could be recovered by the HERDs. Compared to the secondary vertical damper/air spring, the track-related excitation indirectly acted on the HERDs via the wheelset and bogie frame whilst isolating the carbody excitations transmitted from track irregularities. However, this was just an overview and average change trend, and in real applications, the irregularity level of tracks would apply the top-quality track with a smooth surface (I4-I6 track irregularity) to reduce the risk of reliability and stability. Therefore, the average regenerated power would be lower than $20 \mathrm{~W}$ in both the primary and secondary regenerative dampers.
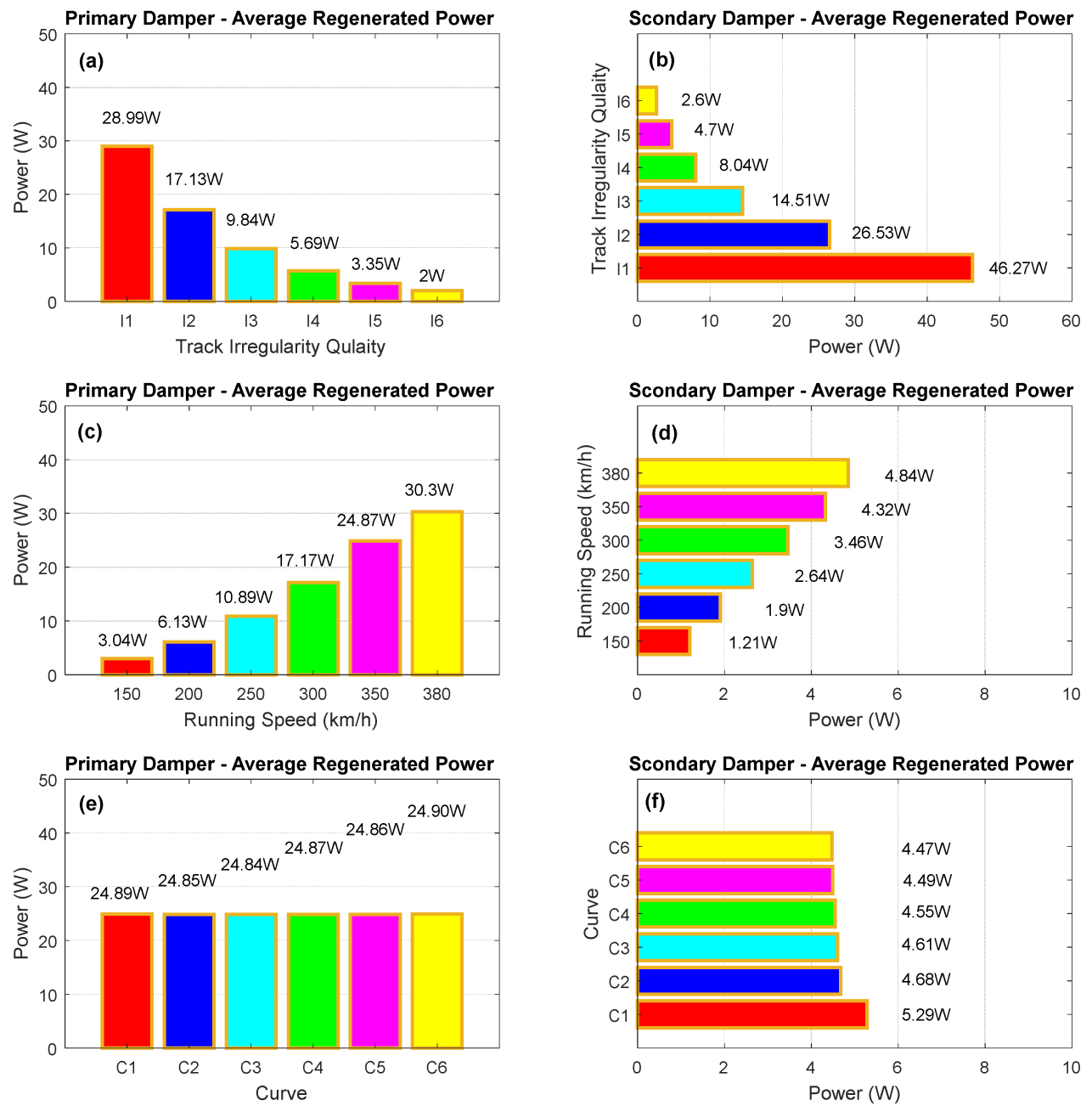

Figure 6. A general view of average power quantities of primary and secondary regenerative dampers: (a,b) Track irregularity quality; (c,d) Running speeds; (e,f) Curves. 

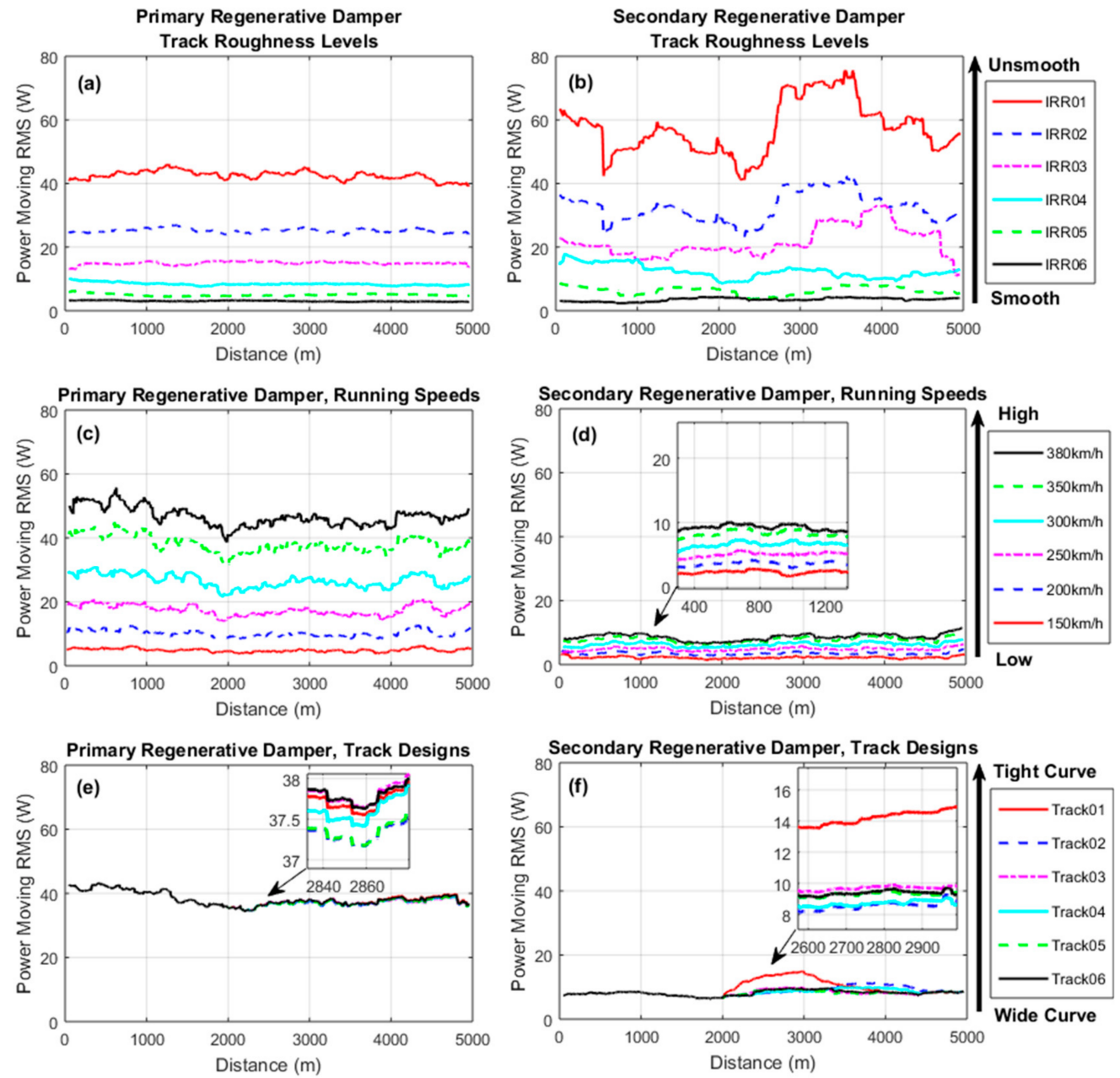

Figure 7. A general view of moving RMS power quantities of primary and secondary regenerative dampers: (a,b) Track roughness levels; (c,d) Running speeds (e,f) Curved tracks.

When considering increasing vehicle speed as the route speed profile and motor traction within the vehicle-damper dynamic model, a considerable amount of regenerated power was continuously generated by both the primary and secondary vertical dampers, as shown in Figure 8e,f. With respect to the speed profile case, it seemed that the average power of the primary damper was $75 \%$ greater than that of the secondary. It was also clear that the average and instantaneous regenerated power of the secondary was significantly smaller than that of the primary. Additionally, the regenerative efficiency of the HERDs had no obvious change with the increase in running speed and driving torque, and remained at a level of $45.62 \%$ and $47.89 \%$, respectively. 

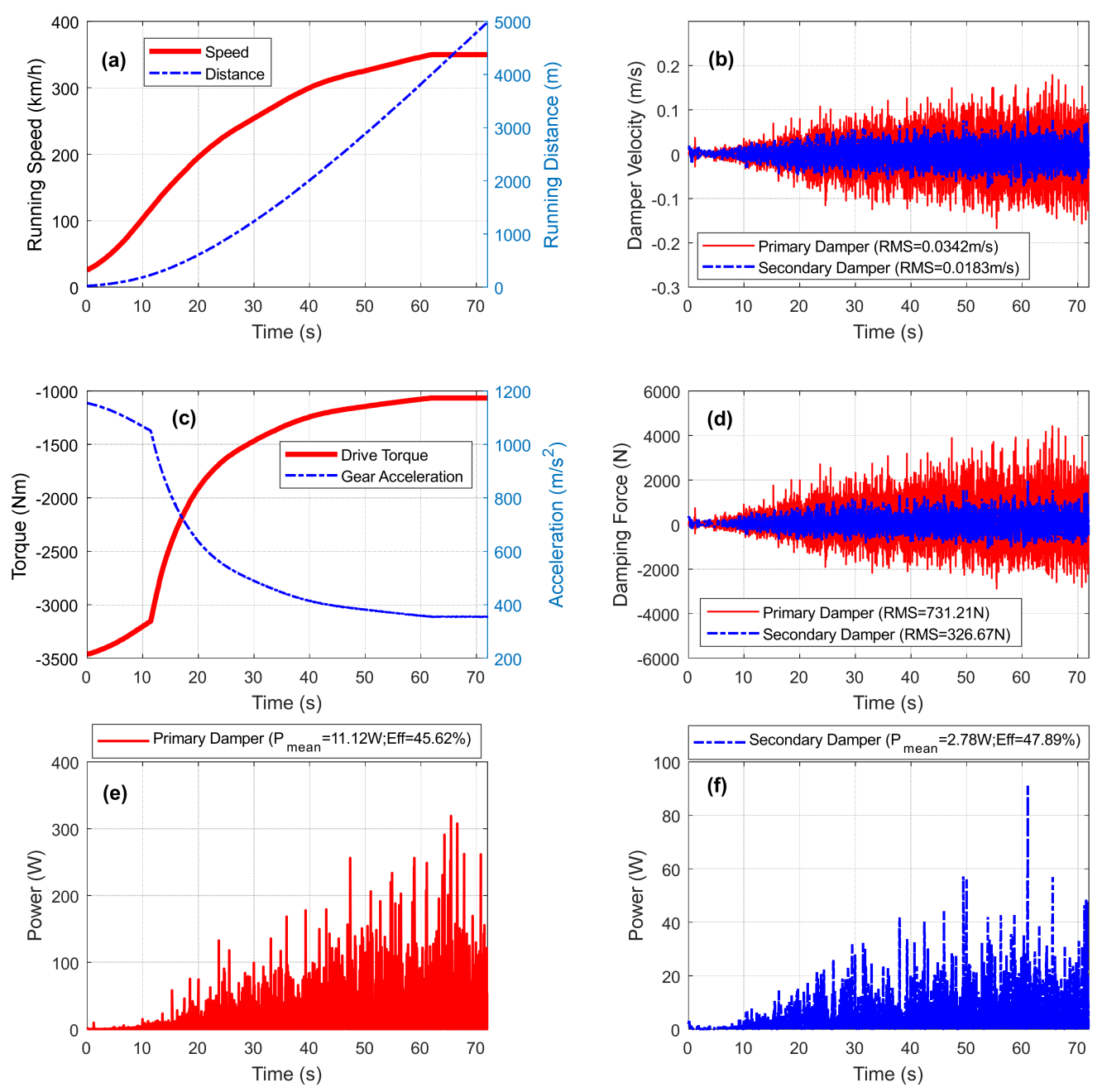

Figure 8. (a) Speed profile design; (b) regenerative damper velocity; (c) calculated drive torque and gear acceleration; (d) damping force; $(\mathbf{e}, \mathbf{f})$ instantaneous regenerated power for primary and secondary dampers.

\subsection{Speed Profile and Instantaneous Power Analysis}

Figure $8 \mathrm{c}$ shows the traction characteristics of a typical high-speed train based on the total traction torque and resulting gear acceleration relative to a predefined speed profile ( 25 to $350 \mathrm{~km} / \mathrm{h}$ ) over a distance of $5 \mathrm{~km}$ (Figure $8 \mathrm{a}$ ). Figure $8 \mathrm{c}$,d show the common feature that the traction torque was dramatically reduced with an increasing running speed, resulting in a decrease in gear acceleration. Within the range of the speed profile, the traction torque and track irregularity were considered as the influencing factors for the longitudinal wheelset acceleration and vertical damper relative velocity in this study.

With previous research experience, in the HERD model, the external load was assumed to be identical to the internal resistance, leading to the maximum regenerative power capability with the minimum damping coefficient for both suspension systems. As shown in Figure 8g, the instantaneous damping characteristics of the primary and secondary dampers were provided at the fixed profile of the speed and traction torque, and the magnitudes of RMS damping force and relative velocity for the primary were nearly double those of the secondary.

Figure 9 shows the variation of the power-velocity characteristic for the cases of highlow vehicle speed, best-worst track irregularity, and varying curve radii for the primary and secondary vertical dampers. As would be expected, Figure $9 \mathrm{a}, \mathrm{b}$ shows that the maximum instantaneous regenerated power occurred at the peak of suspension relative velocity 
and the worst level of track irregularity for both the primary and secondary dampers. In Figure 9e, for the curving comparisons between 'Curve 01' and 'Curve 06 ', instantaneous power showed similar values within the relative velocity range of the primary damper. As shown in Figure 9f, with regards to the secondary damper, the smaller radius 'Curve 01 ' showed a higher damper velocity and extra regenerative capability, but the damper relative velocity had a slight difference in values, as the setting parameters of the curve radius were mainly decided by the ride comfort, maximum running speed, curve actual cant, and maximum allowable cant deficiency. In the case of the curved track, it indicated that the power regeneration was insensitive to the influence of curve changes, as well as the velocity of the damper in service. Obviously, it was found that a high vibration magnitude led to high relative carbody-bogie and bogie-wheelset movement of the damper, which was beneficial for the power-regeneration capability for a fixed damping coefficient in the designated conditions.
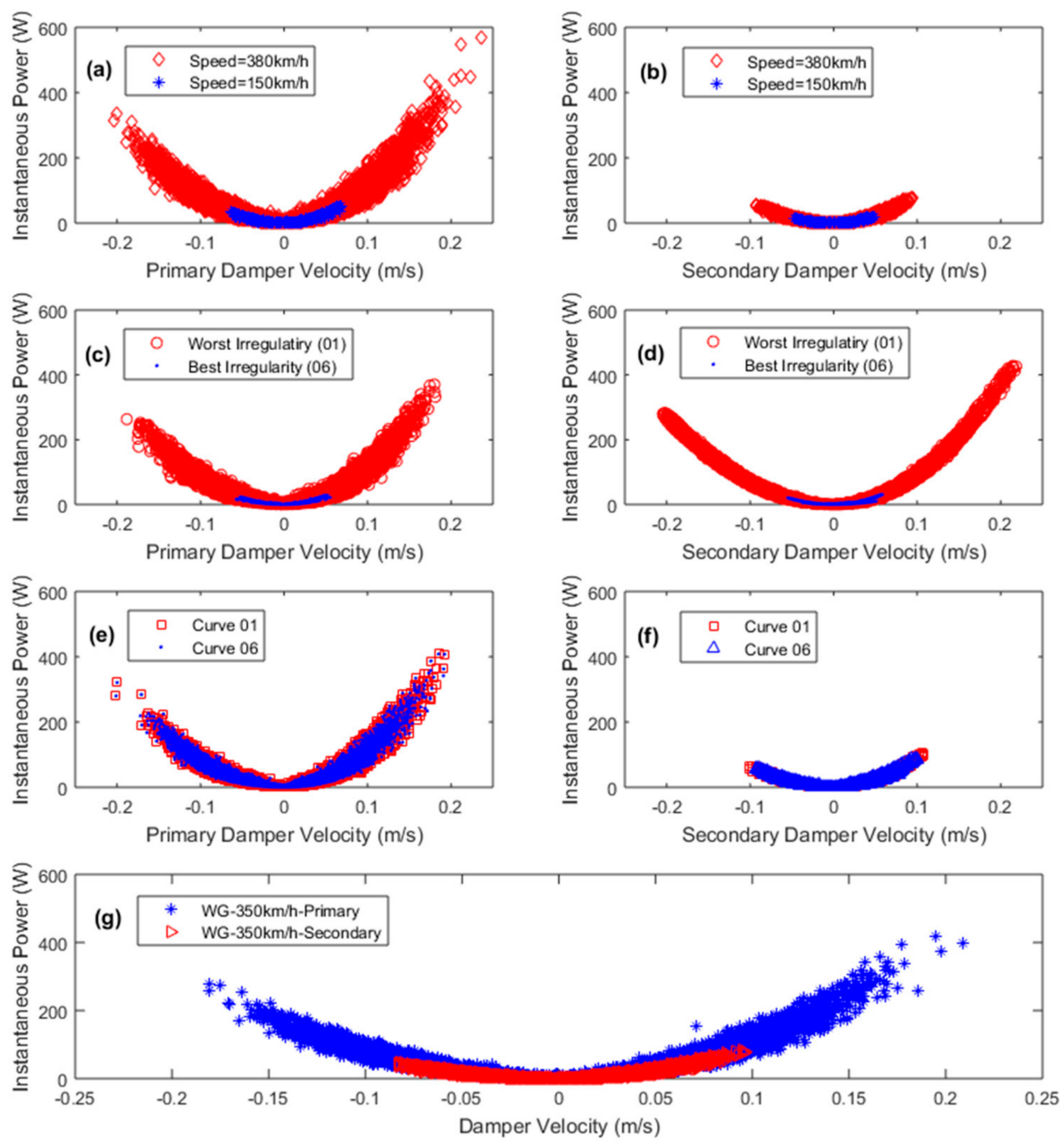

Figure 9. Damper velocity profile of the instantaneous power in case of $(\mathbf{a}, \mathbf{b})$ speed, $(\mathbf{c}, \mathbf{d})$ track irregularity, (e,f) track design, and (g) WG line for primary and secondary regenerative dampers.

\subsection{Loading Comparisons}

The analysis of the instantaneous recoverable power at a high speed of $350 \mathrm{~km} / \mathrm{h}$ and a speed profile of $300-350 \mathrm{~km} / \mathrm{h}$, as in case of the measured straight 'WG' track for tare, fully seated, fully laden, and crush laden conditions, are illustrated in Figures 10 and 11. 

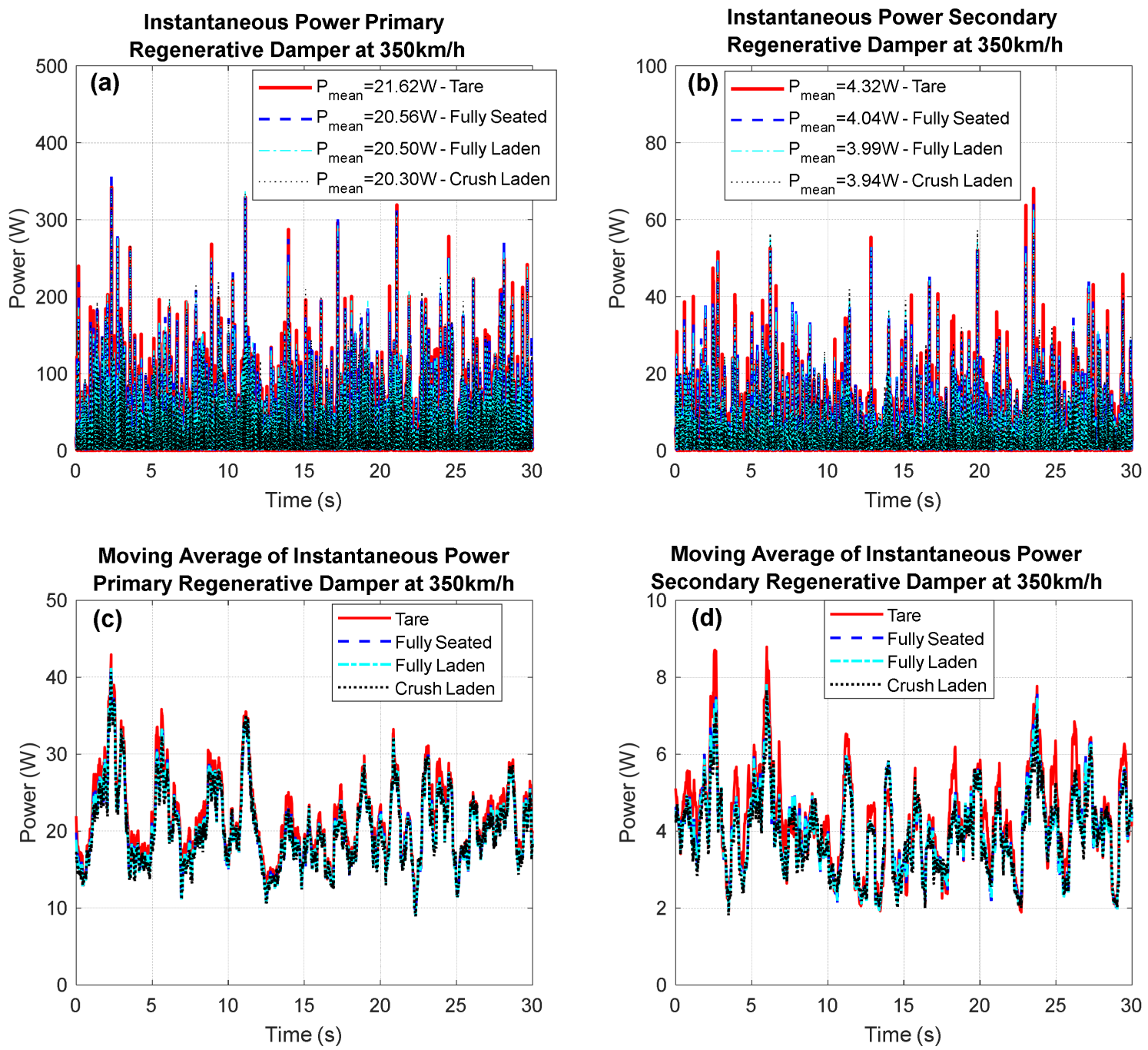

Figure 10. $(\mathbf{a}, \mathbf{b})$ Instantaneous power at the speed of $350 \mathrm{~km} / \mathrm{h}$ for primary and secondary regenerative dampers; (c,d) Moving average of instantaneous power at the speed of $350 \mathrm{~km} / \mathrm{h}$ for primary and secondary regenerative dampers.

With regards to constant speed and the speed profile cases, it seemed that both dampers showed no obvious increase in the instantaneous and average/moving average power magnitude. It is worth mentioning that the journey of a high-speed train is significantly less flexible and more reliable than motor vehicles on the road. Trains have their own specifically designed routes, fixed route distances, high-quality tracks, steady and fast running speeds, and varied loading conditions. These particularities of high-speed train routes contribute to the sustainable performance of power regeneration and cost savings. 

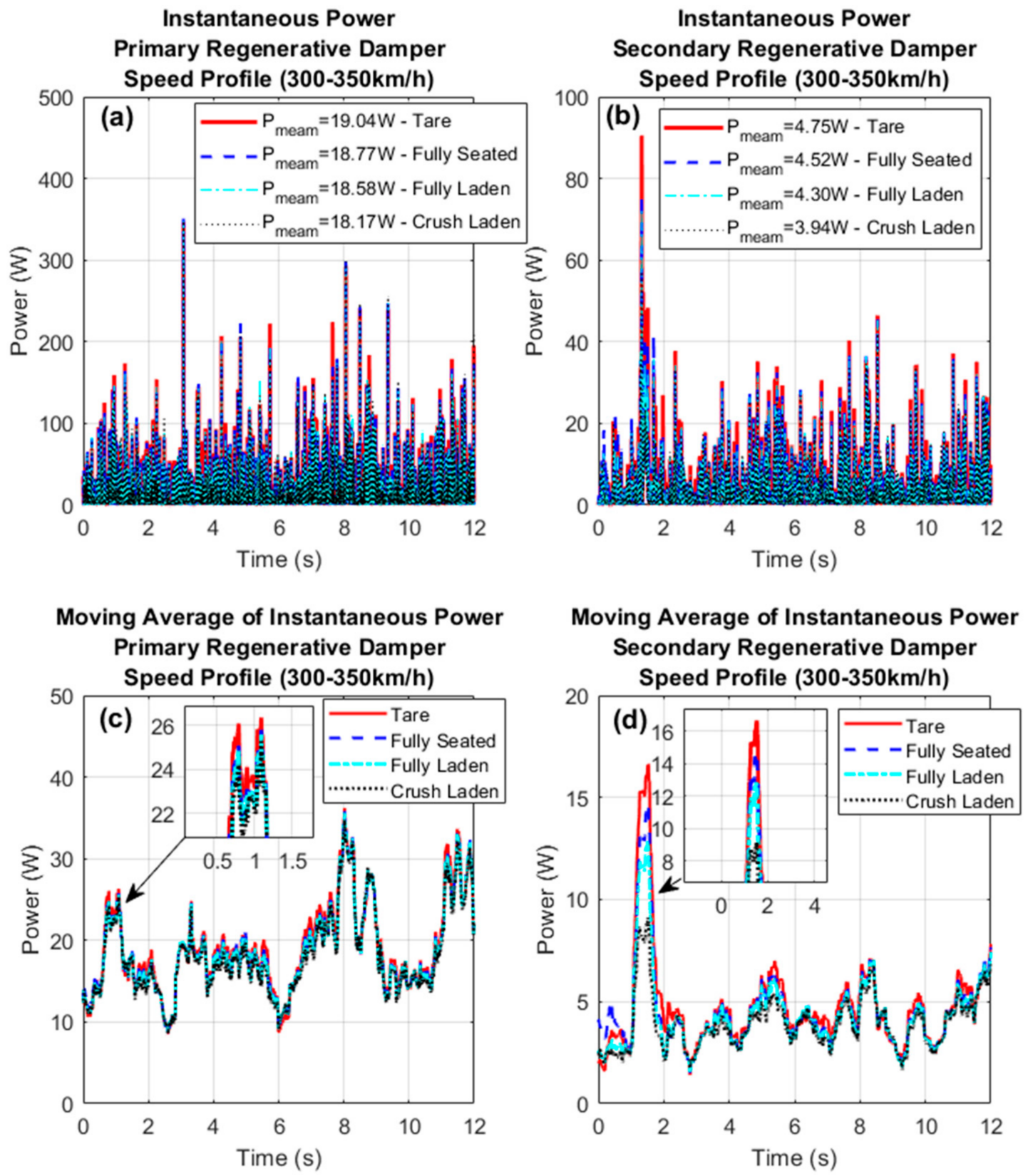

Figure 11. (a,b) Instantaneous power at speed profile (300-350 km/h) for primary and secondary regenerative dampers on various loading conditions; (c,d) Moving average of instantaneous power at speed profile $(300-350 \mathrm{~km} / \mathrm{h})$ for primary and secondary regenerative dampers on various loading conditions.

\section{Conclusions}

A detailed model of a typical high-speed train and an in-service operational pattern with HERDs was modelled to evaluate the power-regeneration capability of the HERD system and the relative performance when installed in the primary and secondary suspension. The results of power performance were analysed using various operating speeds (constant speed and speed profile), loadings, track irregularities, and curve designs. Some key findings can be summarised as follows:

(1) The simulation results indicated that the proposed power-regenerative damper showed considerable potential and recoverable power in the vertical motion direction per damper when applied in both the primary and secondary vertical dampers. The 
analysis revealed that, in the case of a high-speed rail journey, higher levels of track irregularities, higher curve cases, and lower carbody weights were beneficial for power regeneration.

(2) The HERDs could operate effectively in power regeneration whilst negotiating track of different qualities. Using different track irregularities as inputs, the estimations of the regenerated power content were in the range of $2-28.99 \mathrm{~W}$ and $2.6-46.27 \mathrm{~W}$, respectively. These referred to the power per HERD unit of the primary and secondary dampers at a speed of $350 \mathrm{~km} / \mathrm{h}$. A higher vehicle speed was the main influencing factor in maximising power regeneration.

(3) At constant speed, the power potential (total potential power) and regenerative power (HERDs can recover power) on the measured high-speed WG line by the HERDs was not significantly influenced by the curve radius (a range of curve radii and cant deficiencies were studied). Vehicle loading also did not have a great influence, whereas the track quality and vehicle speed were dominant factors. The power capability of the regenerative damper highly depended on the scheduled train operational speed.

(4) According to the design of the power-regenerating damper, the external load resistance was set to be identical to the generator's internal resistance, which could maximise the regenerated power level and efficiency. In the case of a high-speed train profile ( 25 to $350 \mathrm{~km} / \mathrm{h}$ ) over a distance of $5 \mathrm{~km}$, the HERDs could maintain a stable regenerative efficiency of around $45.62 \%$ and $47.89 \%$, respectively. It also was revealed that the average and instantaneous regenerated power of the secondary was significantly smaller than in the primary.

Overall, the performance of the HERD-equipped vehicle showed it could convert kinematic energy into recoverable power at a level that will provide practical use cases without a loss in safety or reliability performance over a realistic range of operating conditions, representing a useful technological development over the conventional vertical dampers of high-speed trains. In the future, further validation will be applied regarding the dynamic behaviours of the vehicle system using the proposed regenerative damper

Author Contributions: R.W.: conceptualisation, methodology, modelling, analysis, and writing. P.A., Y.S. and Z.W.: reviewing and editing. All authors have read and agreed to the published version of the manuscript.

Funding: This research received no external funding.

Institutional Review Board Statement: Not applicable.

Informed Consent Statement: Not applicable.

Data Availability Statement: Not applicable.

Acknowledgments: The University of Huddersfield is licensed by Dassault Systems Deutschland $\mathrm{GmbH}$ to use the SIMPACK software. The first author acknowledges the support of the Norwegian University of Science and Technology (Norway) and Southwest Jiaotong University (China).

Conflicts of Interest: There is no conflict of interest among the authors to publish this article.

\section{References}

1. Goswami, A.; Sen, P. Nanomaterials for Green Energy; Micro and Nano Technologies; Elsevier: Amsterdam, The Netherlands, 2018; ISBN 978-0-12-813731-4.

2. Dang, N.; Bozorgzadeh, E.; Venkatasubramanian, N. Advances in Computers; Elsevier: Amsterdam, The Netherlands, 2012; Volume 87.

3. Beeby, S.P.; Cao, Z.; Almussallam, A. Multidisciplinary Know-How for Smart-Textiles Developers; Woodhead Publishing Series in Textiles; Woodhead Publishing: Sawston, UK, 2013; ISBN 978-0-85709-342-4.

4. Kiziroglou, M.E.; Yeatman, E.M. Functional Materials for Sustainable Energy Applications; Woodhead Publishing Series in Energy; Woodhead Publishing: Sawston, UK, 2012; ISBN 978-0-85709-059-1.

5. Pei, J.; Zhou, B.; Lyu, L. E-Road: The Largest Energy Supply of the Future. Appl. Energy 2019, 241, 174-183. [CrossRef]

6. Zou, H.-X.; Zhao, L.-C.; Gao, Q.-H.; Zuo, L.; Liu, F.-R.; Tan, T.; Wei, K.-X.; Zhang, W.-M. Mechanical Modulations for Enhancing Energy Harvesting: Principles, Methods and Applications. Appl. Energy 2019, 255, 113871. [CrossRef] 
7. Abdelkareem, M.A.A.; Xu, L.; Ali, M.K.A.; Elagouz, A.; Mi, J.; Guo, S.; Liu, Y.; Zuo, L. Vibration Energy Harvesting in Automotive Suspension System: A Detailed Review. Appl. Energy 2018, 229, 672-699. [CrossRef]

8. Abdelkareem, M.A.A.; Xu, L.; Ali, M.K.A.; El-Daly, A.-R.B.M.; Hassan, M.A.; Elagouz, A.; Bo, Y. Analysis of the Prospective Vibrational Energy Harvesting of Heavy-Duty Truck Suspensions: A Simulation Approach. Energy 2019, 173, 332-351. [CrossRef]

9. Gholikhani, M.; Roshani, H.; Dessouky, S.; Papagiannakis, A.T. A Critical Review of Roadway Energy Harvesting Technologies. Appl. Energy 2020, 261, 114388. [CrossRef]

10. Li, C.; Luo, S.; Cole, C.; Spiryagin, M. An Overview: Modern Techniques for Railway Vehicle on-Board Health Monitoring Systems. Veh. Syst. Dyn. 2017, 55, 1045-1070. [CrossRef]

11. Sun, W.; Lu, G.; Ye, C.; Chen, S.; Hou, Y.; Wang, D.; Wang, L.; Oeser, M. The State of the Art: Application of Green Technology in Sustainable Pavement. Adv. Mater. Sci. Eng. 2018, 2018, 9760464. [CrossRef]

12. Song, Y.; Liu, Z.; Rønnquist, A.; Nåvik, P.; Liu, Z. Contact Wire Irregularity Stochastics and Effect on High-Speed Railway Pantograph-Catenary Interactions. IEEE Trans. Instrum. Meas. 2020, 69, 8196-8206. [CrossRef]

13. Song, Y.; Zhang, M.; Øiseth, O.; Rønnquist, A. Wind Deflection Analysis of Railway Catenary under Crosswind Based on Nonlinear Finite Element Model and Wind Tunnel Test. Mech. Mach. Theory 2022, 168, 104608. [CrossRef]

14. Gholikhani, M.; Tahami, S.A.; Khalili, M.; Dessouky, S. Electromagnetic Energy Harvesting Technology: Key to Sustainability in Transportation Systems. Sustainability 2019, 11, 4906. [CrossRef]

15. Buhaug, H.; Urdal, H. An Urbanization Bomb-Population Growth and Social Disorder in Cities. Glob. Environ. Chang. 2013, 23, 1-10. [CrossRef]

16. Bernal, E.; Spiryagin, M.; Cole, C. Onboard Condition Monitoring Sensors, Systems and Techniques for Freight Railway Vehicles: A Review. IEEE Sens. J. 2019, 19, 4-24. [CrossRef]

17. Baptista, M.; de Medeiros, I.P.; Malere, J.P.; Prendinger, H.; Nascimento, C.L.; Henriques, E.M.P. Improved Time-Based Maintenance in Aeronautics with Regressive Support Vector Machines. In Proceedings of the Annual Conference of the Prognostics and Health Monitoring Society, Denver, CO, USA, 3 October 2016; Volume 7, p. 10.

18. Pasquale, G.D.; Somà, A.; Fraccarollo, F. Piezoelectric Energy Harvesting for Autonomous Sensors Network on Safety-Improved Railway Vehicles. Proc. Inst. Mech. Eng. Part C J. Mech. Eng. Sci. 2012, 226, 1107-1117. [CrossRef]

19. Cho, J.Y.; Jeong, S.; Jabbar, H.; Song, Y.; Ahn, J.H.; Kim, J.H.; Jung, H.J.; Yoo, H.H.; Sung, T.H. Piezoelectric Energy Harvesting System with Magnetic Pendulum Movement for Self-Powered Safety Sensor of Trains. Sens. Actuators A Phys. 2016, 250, 210-218. [CrossRef]

20. Wang, J.; Shi, Z.; Xiang, H.; Song, G. Modeling on Energy Harvesting from a Railway System Using Piezoelectric Transducers. Smart Mater. Struct. 2015, 24, 105017. [CrossRef]

21. Nagode, C.; Ahmadian, M.; Taheri, S. Motion-Based Energy Harvesting Devices for Railroad Applications. In Proceedings of the Rail Equipment Engineering, Urbana, IL, USA, 28 October 2010; American Society of Mechanical Engineers Digital Collection; Volume 2, pp. 267-271.

22. Hou, W.; Li, Y.; Guo, W.; Li, J.; Chen, Y.; Duan, X. Railway Vehicle Induced Vibration Energy Harvesting and Saving of Rail Transit Segmental Prefabricated and Assembling Bridges. J. Clean. Prod. 2018, 182, 946-959. [CrossRef]

23. Gao, M.; Wang, P.; Wang, Y.; Yao, L. Self-Powered ZigBee Wireless Sensor Nodes for Railway Condition Monitoring. IEEE Trans. Intell. Transp. Syst. 2018, 19, 900-909. [CrossRef]

24. Siang, J.; Lim, M.H.; Leong, M.S. Review of Vibration-Based Energy Harvesting Technology: Mechanism and Architectural Approach. Int. J. Energy Res. 2018, 42, 1866-1893. [CrossRef]

25. Gao, M.; Wang, P.; Cao, Y.; Chen, R.; Cai, D. Design and Verification of a Rail-Borne Energy Harvester for Powering Wireless Sensor Networks in the Railway Industry. IEEE Trans. Intell. Transp. Syst. 2017, 18, 1596-1609. [CrossRef]

26. Zhang, X.; Zhang, Z.; Pan, H.; Salman, W.; Yuan, Y.; Liu, Y. A Portable High-Efficiency Electromagnetic Energy Harvesting System Using Supercapacitors for Renewable Energy Applications in Railroads. Energy Convers. Manag. 2016, 118, 287-294. [CrossRef]

27. Wang, J.J.; Penamalli, G.P.; Zuo, L. Electromagnetic Energy Harvesting from Train Induced Railway Track Vibrations. In Proceedings of the 2012 IEEE/ASME 8th IEEE/ASME International Conference on Mechatronic and Embedded Systems and Applications, Suzhou, China, 9 July 2012; pp. 29-34.

28. Pourghodrat, A.; Nelson, C.A.; Hansen, S.E.; Kamarajugadda, V.; Platt, S.R. Power Harvesting Systems Design for Railroad Safety. Proc. Inst. Mech. Eng. Part F J. Rail Rapid Transit 2014, 228, 504-521. [CrossRef]

29. Li, Z.; Zuo, L.; Kuang, J.; Luhrs, G. Energy-Harvesting Shock Absorber with a Mechanical Motion Rectifier. Smart Mater. Struct. 2012, 22, 025008. [CrossRef]

30. Pan, Y.; Lin, T.; Qian, F.; Liu, C.; Yu, J.; Zuo, J.; Zuo, L. Modeling and Field-Test of a Compact Electromagnetic Energy Harvester for Railroad Transportation. Appl. Energy 2019, 247, 309-321. [CrossRef]

31. Nelson, C.A.; Platt, S.R.; Albrecht, D.; Kamarajugadda, V.; Fateh, M. Power Harvesting for Railroad Track Health Monitoring Using Piezoelectric and Inductive Devices. In Proceedings of the Active and Passive Smart Structures and Integrated Systems 2008, San Diego, CA, USA, 18 April 2008; Volume 6928.

32. He, X.; Xiao, G.; Hu, B.; Tan, L.; Tang, H.; He, S.; He, Z. The Applications of Energy Regeneration and Conversion Technologies Based on Hydraulic Transmission Systems: A Review. Energy Convers. Manag. 2020, 205, 112413. [CrossRef]

33. Wang, R. Modelling, Testing and Analysis of a Regenerative Hydraulic Shock Absorber System. Ph.D. Thesis, University of Huddersfield, Huddersfield, UK, 2016. 
34. Wang, R.; Crosbee, D.; Iwnicki, S.; Zhao, Y.; Bevan, A. Power Regeneration in the Primary Suspension of a Railway Vehicle. In Proceedings of the First International Conference on Rail Transportation, Chengdu, China, 11 July 2017.

35. Wang, R.; Wang, Z. Evaluation of Power Regeneration in Primary Suspension for a Railway Vehicle. Front. Mech. Eng. 2020, 15, 265-278. [CrossRef]

36. Nagode, C.; Ahmadian, M.; Taheri, S. Effective Energy Harvesting Devices for Railroad Applications. In Proceedings of the Active and Passive Smart Structures and Integrated Systems 2010, San Diego, CA, USA, 9 April 2010; Volume 7643, p. 76430X.

37. Pan, Y.; Liu, F.; Jiang, R.; Tu, Z.; Zuo, L. Modeling and Onboard Test of an Electromagnetic Energy Harvester for Railway Cars. Appl. Energy 2019, 250, 568-581. [CrossRef]

38. Guo, S.; Xu, L.; Liu, Y.; Guo, X.; Zuo, L. Modeling and Experiments of a Hydraulic Electromagnetic Energy-Harvesting Shock Absorber. IEEE/ASME Trans. Mechatron. 2017, 22, 2684-2694. [CrossRef]

39. Wang, R.; Chen, Z.; Xu, H.; Schmidt, K.; Gu, F.; Ball, A.D. Modelling and Validation of a Regenerative Shock Absorber System. In Proceedings of the 2014 20th International Conference on Automation and Computing, Cranfield, UK, 13 September 2014; pp. 32-37.

40. Wang, R.; Gu, F.; Cattley, R.; Ball, A.D. Modelling, Testing and Analysis of a Regenerative Hydraulic Shock Absorber System. Energies 2016, 9, 386. [CrossRef]

41. Zheng, P.; Wang, R.; Gao, J. A Comprehensive Review on Regenerative Shock Absorber Systems. J. Vib. Eng. Technol. 2020, 8 , 225-246. [CrossRef]

42. Wang, Z.; Song, Y.; Yin, Z.; Wang, R.; Zhang, W. Random Response Analysis of Axle-Box Bearing of a High-Speed Train Excited by Crosswinds and Track Irregularities. IEEE Trans. Veh. Technol. 2019, 68, 10607-10617. [CrossRef]

43. Wang, Z.; Allen, P.; Mei, G.; Wang, R.; Yin, Z.; Zhang, W. Influence of Wheel-Polygonal Wear on the Dynamic Forces within the Axle-Box Bearing of a High-Speed Train. Veh. Syst. Dyn. 2020, 58, 1385-1406. [CrossRef]

44. Wang, Z.; Wang, R.; Crosbee, D.; Allen, P.; Ye, Y.; Zhang, W. Wheel Wear Analysis of Motor and Unpowered Car of a High-Speed Train. Wear 2020, 444-445, 203136. [CrossRef]

45. Wang, Z.; Yin, Z.; Wang, R.; Cheng, Y.; Allen, P.; Zhang, W. Coupled Dynamic Behaviour of a Transmission System with Gear Eccentricities for a High-Speed Train. Veh. Syst. Dyn. 2021, 59, 613-634. [CrossRef]

46. Song, Y.; Wang, Z.; Liu, Z.; Wang, R. A Spatial Coupling Model to Study Dynamic Performance of Pantograph-Catenary with Vehicle-Track Excitation. Mech. Syst. Signal Process. 2021, 151, 107336. [CrossRef]

47. Wang, Z.; Yin, Z.; Allen, P.; Wang, R.; Xiong, Q.; Zhu, Y. Dynamic Analysis of Enhanced Gear Transmissions in the Vehicle-Track Coupled Dynamic System of a High-Speed Train. Veh. Syst. Dyn. 2021, 1-23. [CrossRef]

48. Wang, Z.; Mei, G.; Zhang, W.; Cheng, Y.; Huang, G.; Li, F. Effects of Polygonal Wear of Wheels on the Dynamic Performance of the Gearbox Housing of a High-Speed Train. Proc. Inst. Mech. Eng. Part F J. Rail Rapid Transit 2018, 232, 1852-1863. [CrossRef]

49. Zhai, W. Vehicle - Track Coupled Dynamics; Springer: Singapore, 2020; ISBN 978-981-329-283-3.

50. Connor, P. Railway Passenger Vehicle Capacity; PRC Rail Consulting Ltd.: Derby, UK, 2011. Available online: http:/ /www.railwaytechnical.com/books-papers--articles/infopaper-2-railway-passeng.pdf (accessed on 15 February 2022).

51. EN 15663:2017 BS EN 15663:2017+A1:2018; Railway Applications-Vehicle Reference Masses; The British Standards Institution: London, UK, 2017. 